\title{
A atualidade da obra de Mary Wollstonecraft
}

\author{
Reivindicação dos direitos da \\ mulher. \\ WOLLSTONECRAFT, Mary. \\ Trad. de Ivania Pocinho Motta. São Paulo: \\ Boitempo, 2016.
}

A leitura de Reivindicação dos Direitos da Mulher, texto escrito por Mary Wollstonecraft em 1792, é inquietante. Como uma obra de mais de duzentos anos pode retratar elementos ainda tão presentes em nossa sociedade, como a desigualdade de gênero no campo político, a discriminação de gênero na educação e a inferiorização das mulheres nas sociedades ocidentais? Como questões como estas, levantadas como problemáticas e injustas no passado podem se perpetuar de tal maneira?

A obra se insere entre as leituras fundamentais para o feminismo, pois, como sugere a própria autora, o estudo é imprescindível para romper com as estruturas que colocam as mulheres em posição de submissão e inferioridade em relação aos homens. Reconhecendo que a desigualdade de gênero ainda existe, a compreensão da historicidade de tal realidade e das lutas por transformações sociais é relevante para a continuidade dos esforços em prol da mudança.

Mary Wollstonecraft (1759-1797) foi uma intelectual libertária inglesa que abraçou as causas de pessoas oprimidas de seu tempo, sendo hoje reconhecida como uma importante abolicionista inglesa e uma das precursoras do feminismo. A edição comentada de sua obra clássica é enriquecida com o prefácio de Maria Lygia Quartim de Moraes, socióloga, pesquisadora do PAGU Núcleo de Estudos de Gênero da UNICAMP que contextualiza a publicação, na discussão de duas outras personagens significativas: a francesa Olympe de Gouges - que, da mesma forma e na mesma época de Mary Wollstonecraft - lutou contra a escravidão e pelos direitos das mulheres, fundamentando-se, como ela, no legado iluminista e principalmente contribuindo com ele com suas reflexões e escritos; e a brasi-leira Nísia Floresta - apontada como precursora do feminismo no Brasil - que em 1832 escreveu Direitos das Mulheres e Injustiça dos Homens.

A publicação traz ainda uma breve cronologia de sua conturbada e revolucionária vida, desde a saída da casa do autoritário pai, na busca de autonomia financeira, à fundação de uma escola em Newington Green em parceria com sua irmã - quem Mary ajudou a se afastar do marido violento -, até sua incursão no mundo intelectual, as angústias que a fizeram tentar o suicídio por duas vezes, bem como as relações afetivas consideradas fora do padrão para a época em que viveu e pelas quais sofreu as mazelas do preconceito. Por fim, sua morte, aos 38 anos de idade, em decorrência de complicações do seu segundo parto, da filha Mary Wollstonecraft Godwin, mais conhecida como Mary Shelley, autora do romance Frankenstein. Reivindicação dos direitos da mulher é bastante provocativa, na medida em que, conforme afirmou a autora, pretendia ser útil e, além disso, entendia que a sinceridade era mais eficaz do que uma fabricação retórica artificial. Por isso, foi direta em sua escrita, abordando questões essenciais sobre política e educação, denunciando as condições desiguais entre homens e mulheres que as colocavam em situação de inferioridade. Era uma intelectual reconhecida já em sua época, que demonstrava uma preocupação social intensa, pois queria transformar a sociedade, motivo pelo qual colocou sua escrita a este serviço. Tal perspectiva remete-nos à expressão de Joan Scott (1994, p. 19), que muitos anos depois, nos convidou a traçar esse mesmo caminho ao afirmar que "o 
historiador pode interpretar o mundo ao mesmo tempo que tenta transformá-lo".

Em diferentes momentos do texto há a sensação de que nossos apelos por justiça social são ecos da voz de Wollstonecraft. A autora argumenta que muitos homens, incluindo intelectuais, ao se depararem com suas reivindicações tentavam "ridicularizar os argumentos" que, segundo ela, não podiam rebater. $E$ isso ainda ocorre, principalmente em relação ao feminismo, que nem sempre é compreendido, sendo muitas vezes criticado ou menosprezado por meio de narrativas superficiais que demonstram a falta de argumentos coerentes, a falta de conhecimento sobre $o$ assunto e o machismo tão presente em nossa sociedade. Outras questões são destacadas em Reivindicação dos Direitos da Mulher: a necessidade de as mulheres buscarem autonomia, seja financeira ou emocional, bem como a luta pelo direito das mulheres à educação formal transformadora. Wollstonecraft salienta, ainda, a importância de as mulheres conquistarem espaço no campo político e dizerem não ao confinamento doméstico e critica a demasiada valorização de títulos e posições sociais que nem sempre significam competência efetiva - alerta que faz a homens e mulheres. Os riscos do encantamento com a moda e a preocupação com beleza exterior, que exclui o desenvolvimento intelectual, modo de objetificação das mulheres, é outro tema abordado pela escritora e que continua sendo, como os demais pontos apresentados, objeto de discussão na sociedade atual.

Isabel Martinez Benlloch (2005), em Construcción psicosocial de los modelos de género, trata do que chama de mitos da feminilidade $e$ da masculinidade, cuja internalização traz consequências trágicas, tais como a violência. Entre os mitos da feminilidade, apontados por ela, estó a crença no poder do amor romântico, entendido como submisso e dependente, e a idealização das mulheres como objetos desse amor, enfatizando seu papel social de esposas e mães. A consequência disso é a dependência emocional e/ou econômica. Apegadas às ideias de abnegação, renúncias e sacrifícios em prol das familias - principalmente dos filhos e filhas -, as mulheres deixam de lado projetos pessoais que poderiam dar-Ihes autonomia, como o estudo e o trabalho remunerado. Mary Wollstonecraft já afirmava em 1792 que considerava "a independência a grande benção da vida. A base de toda virtude" (WOLLSTONECRAFT, 2016, p. 17).

A ideia de autonomia proposta pela autora não condena a vivência familiar, a maternidade ou o casamento, mas critica a imposição social em detrimento do direito a uma educação que permitisse que $o$ saber conduzisse a escolhas conscientes. A fragilidade imputada às mulheres era resultado de uma educação que fazia com que se preocupassem mais com a beleza exterior do que com o desenvolvimento do seu intelecto.

O entendimento do sexo feminino tem sido tão distorcido por essa homenagem ilusória que as mulheres civilizadas de nosso século, com raras exceções, anseiam apenas inspirar amor quando deveriam nutrir uma ambição mais nobre e exigir respeito por suas capacidades $\mathrm{e}$ virtudes. (WOLLSTONECRAFT, 2016, p. 25)

A atualidade da obra é inegável neste momento em que o Brasil vivenciou uma tensa situação política que culminou com o afastamento definitivo da presidenta Dilma Rousseff, democraticamente eleita, em uma ação tão fortemente marcada por questões de gênero e que teve como uma das consequências o fim do Ministério das Mulheres, da Igualdade Social e dos Direitos Humanos. A repercussão internacional de uma matéria escrita por Juliana Linhares (2016) e publicada no período de julgamento do afastamento ou não da presidenta, sobre a esposa do então vice-presidente Michel Temer, intitulada 'Marcela Temer: Bela, recatada e do lar' , por uma revista com interesses claramente políticos, é significativa. A publicação é, aqui, interpretada como tentativa de deslegitimar a ocupação por uma mulher do cargo político mais importante do país. A matéria visou ressaltar, em pleno século $X X I$, que o papel adequado para uma mulher é - de esposa e mãe e seu espaço de ação deve ser o da casa e náo o político, devendo portar-se de forma recatada, atuando de forma subordinada aos padrões considerados ideais por uma sociedade conservadora.

Wollstonecraft questionava já no século XVIII a ausência de mulheres no espaço político. Afirmou sobre a importância de existirem mulheres tomando decisões na assembleia legislativa, de pensarem em leis que garantissem seus direitos. Salientava que mulheres e homens compartilham o "dom da razão" (WOLLSTONECRAFT, 2016, p. 19) e que, portanto, os homens não deviam se considerar como os únicos capacitados para as decisões políticas. A autora denunciou a intenção masculina de converter as mulheres "em objetos de atração momentânea" (WOLLSTONECRAFT, 2016, p. 26), belas, recatadas e do lar, e alertava sobre "exclamações de todas as partes contra mulheres masculinas", que seriam aquelas que 
ousavam estudar e ocupar espaços, entendidos no período como masculinos.

Em tom irônico argumentou: "Espero que meu próprio sexo me desculpe caso eu trate as mulheres como criaturas racionais, em vez de adula suas graças fascinantes e considerá-las como se estivessem em um estado de perpétua infância incapazes de ficar sozinhas" (WOLLSTONECRAFT, 2016 p. 27). Visava, com isso, persuadir as mulheres a se fortalecerem intelectualmente, desdenhando, inclusive, o que ela chamou de "frases condescendentes masculinas" (WOLLSTONECRAFT, 2016, p. 27): embora encantadoras, almejavam apenas mantê-las em lugar de submissão. Para a escritora, as mulheres deveriam se tornar mais masculinas, no sentido de buscarem o conhecimento e a ação política, já que isso era considerado masculino, porque a ideia de fragilidade $e$ incompetência para o espaço público não era algo dado, mas socialmente construído. Ela, antes de Simone de Beauvoir que escreveu $O$ segundo sexo em 1949, denunciou as construções sociais de gênero que inferiorizam as mulheres.

Reivindicação dos direitos da Mulher é composta por treze capítulos nos quais a autora discorre sobre os mais diversos temas, evidenciando sempre o problema da inferiorização das mulheres e a necessidade da autonomia feminina. Ela elabora apontamentos sobre a educação nacional, sobre a escrita de manuais para a educação de mulheres realizada por homens, sobre relações familiares, dedicando, inclusive, um capítulo para discutir o afeto parental e outro dedicado a repensar o dever dos filhos para com os pais, problematizando a obediência cega aos "tiranos de qualquer tipo" (WOLLSTONECRAFT, 2016, p. 195), fossem reis ou pais. Wollstonecraft critica também a autoridade de quem assume o poder de forma criminosa, reis ou outras lideranças, e discorda da estruturação hierárquica de determinadas instituições, como o exército, por exemplo, que ao congregar soldados jovens e imaturos, sem uma formação intelectual adequada, apenas fazia com que seguissem as ordens, por vezes lutando sem saber ou sem querer saber o motivo, não tendo, portanto, autonomia e capacidade para formularem opiniões e tomarem as próprias decisões.

Evidentemente, Reivindicação dos direitos da Mulher precisa ser lida como sintomática a seu tempo, seja no que tange às relações políticas que ela problematiza, seja no caráter religioso de algumas afirmações e posicionamentos, mas é inegável que, em muitos aspectos, pode ser considerada como uma leitura importante para o feminismo atual por tocar em pontos ainda não resolvidos. A luta pela autonomia de mulheres em situação de violência e que sofrem pela dependência emocional e/ou financeira ainda é realidade, a educação de meninos e meninas ainda ocorre de forma a diferenciá-las em termos de competências e a ocupação do espaço político ainda é pauta de luta. Muito se conquistou, mas muito há que se conquistar.

Por fim, podemos afirmar que a questão mais contundente levantada pela obra está na relevância da educação como possibilidade de transformação social, na construção do conhecimento para a superação da aceitação servil de opiniões alheias. Para Mary Wollstonecraft (2016, p. 132), o "ser que pode governar a si próprio não tem nada a temer na vida", e essa capacidade de governar-se é adquirida pelo desenvolvimento intelectual que instrumentaliza para a tomada de decisões conscientes e mobiliza para o enfrentamento de preconceitos e de opressões.

\section{Referências}

BEAUVOIR, Simone de. O segundo Sexo. II A Experiência vivida. 2.ed. São Paulo: Difusão Europeia do Livro, 1967.

BENLLOCH, Isabel Martinez. Construcción psicosocial de los modelos de género: subjetividad y nuevas formas de sexismo. In: CASTILLOMARTíN, Márcia; OLIVEIRA, Suely. Marcadas a ferro: violência contra a mulher, uma visão interdisciplinar. Brasília: Secretaria Especial de Políticas para as Mulheres, 2005, p. 104-134.

LINHARES, Juliana. Marcela Temer: bela, recatada e do lar. Revista Veja, 18 de abril de 2016. Disponível em: http://veja.abril.com.br/noticia/ brasil/bela-recatada-e-do-lar. Acesso em 25/ 09/2016.

sCOT, Joan. "O gênero na História: a categoria da diferença na escrita da História". Debate Scott, Tilly e Varikas. Cadernos Pagu (3), p. 11 84, 1994.

WOLLSTONECRAFT, Mary. Reivindicação dos direitos da mulher. Trad. de Ivania Pocinho Motta. São Paulo: Boitempo, 2016.

Dulceli de Lourdes Tonet Estacheski Universidade Federal de Santa Catarina, Florianópolis, Santa Catarina, Brasil

Talita Gonçalves de Medeiros Universidade Federal de Santa Catarina Florianópolis, Santa Catarina, Brasil

[Recebida em 10/06/2016 e aceita para publicação em 31/08/2016] 
Dulceli de Lourdes Tonet Estacheski (dulce_tonet@yahoo.com.br). Mestra em História pela Universidade Federal do Paraná com a dissertação: Crimes Sexuais em Castro/ PR (1890-1940), é professora do curso de História da Universidade Estadual do Paraná, campus de União da Vitória, e doutoranda do Programa de Pós-Graduação em História da Universidade Federal de Santa Catarina, linha de pesquisa Relações de Poder e Subjetividades, sob orientação da Dra. Cristina Scheibe Wolff.
Talita Gonçalves de Medeiros (tgmhistoria@gmail.com). É mestra em História pela Universidade Federal do Rio Grande, com a dissertação: O que eu sei, o que eu acho e o que me disseram: diálogos com jovens sobre lesbianidades. Doutoranda do Programa de Pós-Graduação em História da Universidade Federal de Santa Catarina, pela linha de pesquisa Relações de Poder e Subjetividades, com a orientação da Dra. Joana Maria Pedro. 